\title{
COMPREHENSIVE STUDY OF SWASH-ZONE HYDRODYNAMICS AND SEDIMENT TRANSPORT
}

\author{
Jack A. Puleo ${ }^{1}$, Chris Blenkinsopp ${ }^{2}$, Daniel Conley ${ }^{3}$, Gerd Masselink ${ }^{3}$, Paul Russell ${ }^{3}$, Ian \\ Turner $^{2}$, Daniel Buscombe ${ }^{3}$, Thijs Lanckriet ${ }^{1}$, Robert McCall ${ }^{3}$ and Timothy Poate ${ }^{3}$
}

\begin{abstract}
A comprehensive study of swash-zone sediment transport was conducted on a macro-tidal beach in Perranporth, UK. The unique study is the first to simultaneously measure suspended sediment and sheet flow sediment concentrations and near bed velocity on a natural beach. Data collected during the study will be used to address the importance of sheet flow processes on swash zone sediment transport and morphology, the variability in the near bed velocity profile and the importance of alongshore and vertical flows, cross-shore advection of turbulence and the inference of swash zone forcing and momentum transfer from remotely sensed data.
\end{abstract}

Keywords: swash zone, sediment transport, sheet flow

\section{INTRODUCTION}

Understanding nearshore sediment transport requires knowledge of the hydrodynamic and morphodynamic processes occurring across a range of temporal and spatial scales. The swash zone, the region where wave-driven flows alternately wash up and down the beach face, is one region of the nearshore where sediment transport understanding and prediction is particularly difficult. Rapid, shallow ephemeral flows with large sediment loads can hamper in situ velocity and sediment transport measurements.

Swash-zone sediment transport is generally studied using current meters and optical backscatter sensors (Masselink et al. 2005; Puleo et al. 2000) that are designed for suspended load (supported by turbulent fluctuations). The product of the velocity and concentration measurement is used to determine the sediment transport rate at a given elevation above the bed. Improved vertical resolution is attainable with an array of optical backscatter sensors, but their size, even though small, often precludes their use in this way for swash zone flows. Instead, fiber optic backscatter sensors (FOBS) are used because the sensor size and sampling volume are small enabling a sediment concentration profile at up to $0.01 \mathrm{~m}$ resolution to be obtained (e.g. Puleo et al. 2000). FOBS data have provided improved insight into the suspended sediment transport processes occurring in the swash zone such as the variability in elevation and duration of the suspension peaks during uprush and backwash. However, neither OBS nor FOBS provide any information on sediment transport processes occurring in the direct vicinity of the bed. Swash-zone sediment transport also contains a bedload or sheet flow component of unknown magnitude in relation to sediment fluxes higher in the water column. Past research investigating integrated transport has suggested the importance of nearbed sediment transport (Horn and Mason 1994) and other limited in situ data (Yu et al. 1990) have indicated the magnitude of the nearbed sediment transport signal. Gradients in the total load transport (bedload plus suspended load), regardless of the dominant transport mode, drive small-scale morphological change on an interswash basis (Blenkinsopp et al. 2011) that over time can lead to significant net morphological change.

The $1^{\text {st }}$ International Workshop on Swash-Zone Processes (Puleo and Butt 2006), convened in 2004, further identified the deficiencies described above. As a culmination of the collaborative efforts initiated during the workshop, a first-of-its-kind Beach Sediment Transport (BeST) study that simultaneously measured instantaneous water depth, velocity profiles, turbulent kinetic energy, sediment concentration from the at-rest bed up through the water column and inter-swash morphological change was conducted in October 2011 to address these key swash-zone processes. This proceedings paper describes the framework for the study undertaken and presents some preliminary results.

\section{FIELD SITE AND SENSOR DEPLOYMENT}

The BeST field study occurred from 9-15 October, 2011 on Perranporth Beach in Cornwall, United Kingdom (Figure 1). Perrenaporth Beach is a low-sloping macrotidal beach with a mean tidal range of $5.43 \mathrm{~m}$. Measurements during the BeST campaign were collected spanning high tide, with durations of 3-4 hours, for 10 tidal cycles across a spring tide sequence (Figure 2, grey shaded regions). The upper panel shows the predicted tidal level. These particular tidal sequences were chosen because the high

\footnotetext{
${ }^{1}$ Center for Applied Coastal Research, University of Delaware, Newark, DE 19716, USA

${ }^{2}$ Water Research Laboratory, School of Civil and Environmental Engineering, University of New South Wales, Sydney, Australia

${ }^{3}$ School of Marine Science and Engineering, Plymouth University, Drake Circus, Plymouth, PL4 8AA, UK
} 
tides were all centered around 3 m Ordnance Datum Newlyn (ODN). The significant wave height (Figure 2B) and spectral peak period (Figure 2C) were measured in approximately $10 \mathrm{~m}$ water depth by a Datawell Directional Waverider buoy (Channel Coastal Observatory; www.channelcoast.org). Significant wave height at the beginning of the study was nearly $3 \mathrm{~m}$. The significant wave height decreased over the remaining tidal cycles until it was just larger than $0.5 \mathrm{~m}$ on the last high tide. Spectral peak period was of the order of $10 \mathrm{~s}$ for the first 4 tidal cycles before increasing to around $15 \mathrm{~s}$ before the $5^{\text {th }}$ tidal cycle. Spectral peak period then decreased over the remainder of the experiment until it was again nearly $10 \mathrm{~s}$ during the last tidal cycle. The offshore peak direction varied by up to $30^{\circ}$ relative to shore normal (the dashed horizontal line in Figure 2D). Wave direction shows variability throughout the tidal cycle implying that tidal effects at the location of the buoy play an important role in the depth influence on wave refraction. However, the wave obliquity in the surf and swash zones did not seem to exhibit this much spread about shore normal. In addition, Perranporth Beach is protected by headlands to the north and south whose influence on the incoming waves may depend on tidal level.
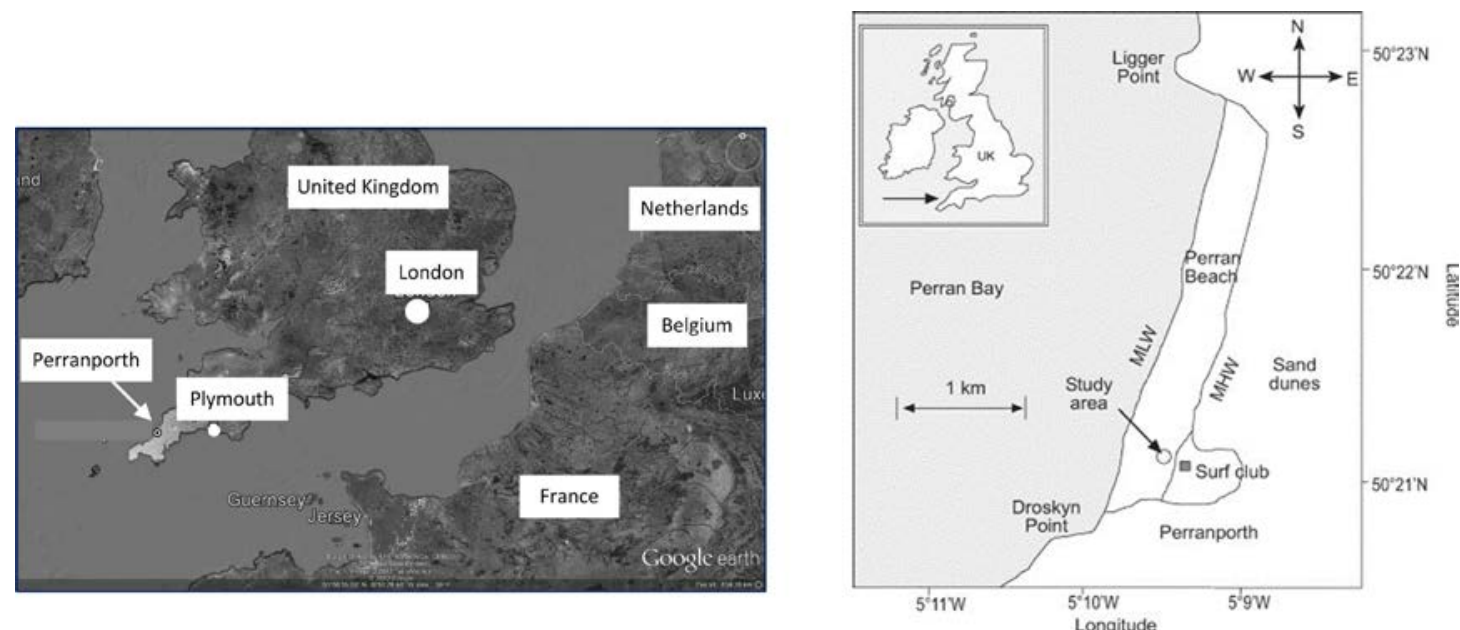

Figure 1. Location of Perranporth Beach UK (left) and map (Masselink et al., 2005) showing the study area (right). Image on left obtained from Google Earth.

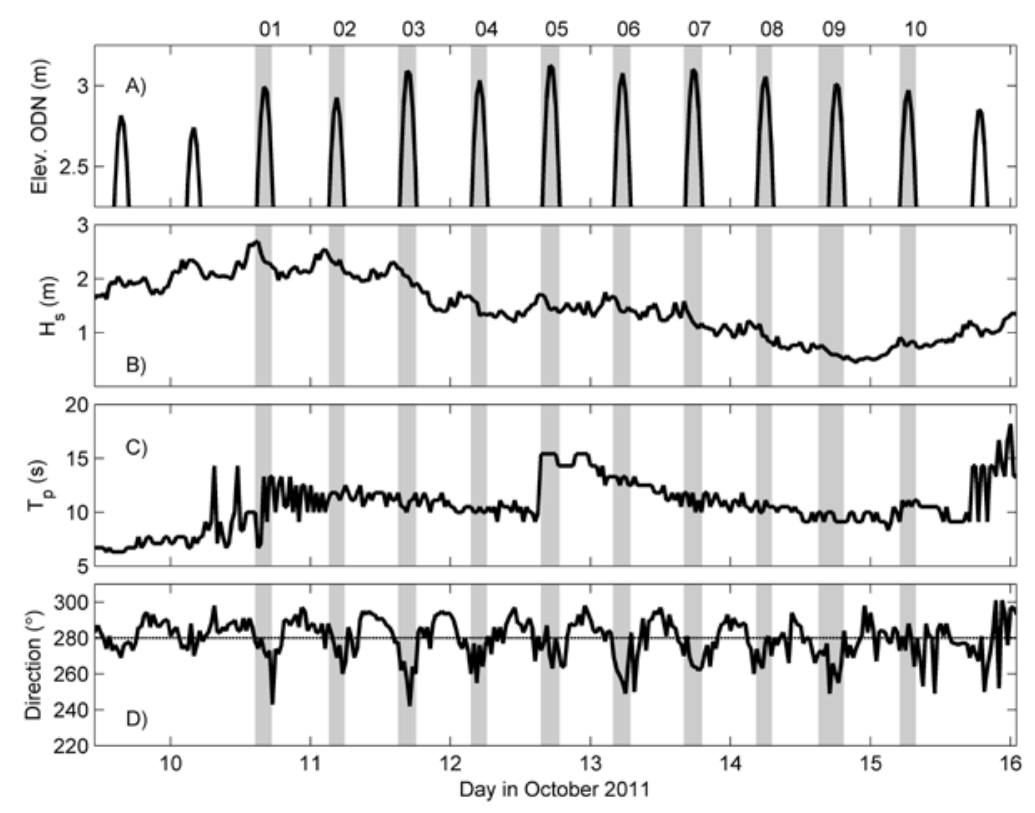

Figure 2. Forcing conditions for the BeST study. A) Tide level, B) Significant wave height, C) Spectral peak period and D) wave direction. Horizontal dashed line is shore normal incidence. Grey shading in all plots indicates the sampling period and tide number denoted by values on the upper axis of (A). 
A $45 \mathrm{~m}$ long scaffold frame was installed near the high tide line for mounting sensors (Figure 3A). A local right-handed coordinate system was established with cross-shore distance, $x$, increasing onshore. Forty-five ultrasonic distance meters (UDM; Massa M300/95) were installed at an elevation approximately $1 \mathrm{~m}$ above the bed at one meter intervals spanning the length of the frame. Each UDM measures the free surface when the area below it is wetted or the sand elevation when the area below it is exposed. Thus, the sensors yield cross-shore time series of water depth and morphological change in the swash zone (Blenkinsopp et al. 2011; Turner et al. 2008). UDMs were sampled at $4 \mathrm{~Hz}$. A SiCK LiDAR line scanner (SiCK LMS511) was erected on a scaffold pole at an elevation of $5 \mathrm{~m}$ above the bed to obtain complimentary measurements to the ultrasonic distance meters (Blenkinsopp et al. 2010). The line scanner is more highly resolved in the cross-shore than UDMs with an angular resolution of 0.25 degrees leading to a cross-shore spatial resolution of $0.025 \mathrm{~m}$ near the scanner and 0.2 to $0.4 \mathrm{~m}$ near the landward and seaward ends of the scaffold frame respectively. The line scanner was sampled at $35 \mathrm{~Hz}$. A nearbed pressure sensor (Druck PTX1830) for measuring forcing conditions was deployed $5 \mathrm{~m}$ seaward of the offshore end of the scaffold frame and sampled at $4 \mathrm{~Hz}$.
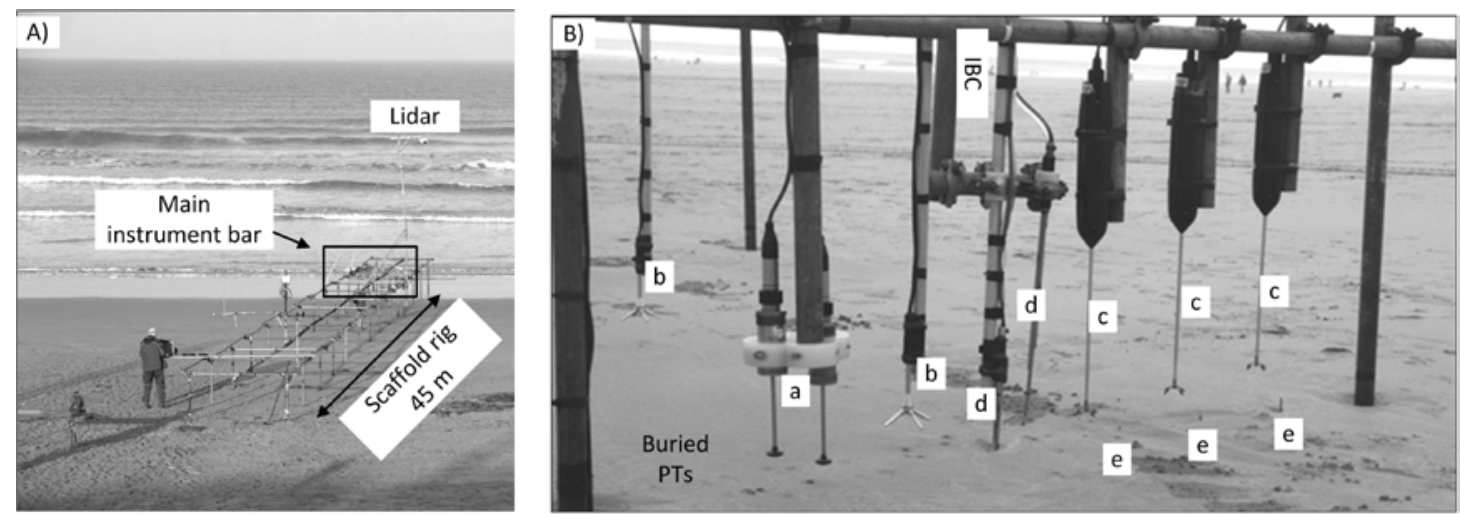

Figure 3. Images showing the scaffold frame (A) and the main instrument bar (B). Sensors on the main instrument are: electromagnetic current meters (a), Vectrino I velocimeters (b), Vectrino II acoustic Doppler current profilers (c), FOBS (d) and CCPs (e). The buried Pressure transducers (PTs) and in situ bed cam are only identified by their names in the photo.

Other swash-zone measurements were largely concentrated on a main instrument bar (Figure 3B). Cross-shore and alongshore velocities ( $u, v$ respectively) were recorded with two Valeport electromagnetic current meters positioned nominally at 0.03 and $0.06 \mathrm{~m}$ above the bed (Figure 3B,a). The cross-shore distribution of velocity and turbulence was recorded with 3 Nortek Vectrino I acoustic velocimeters (Figure 3B,b). Each sensor measures the three velocity components $(u, v, w$, where $w$ is the vertical velocity) at nominally $0.05 \mathrm{~m}$ above the bed. One Vectrino I was located on the main bar with another located $1.5 \mathrm{~m}$ seaward (Figure 3B,b) and the third1.5 m landward (Not visible in Figure 3B). Vectrino I sensors were sampled at $100 \mathrm{~Hz}$. Highly-resolved near bed velocity profiles $(u, v, w)$ were recorded with 3 Vectrino II acoustic Doppler current profilers (ADCP; Figure 3B,c). The ADCPs record the velocity profile at $0.001 \mathrm{~m}$ vertical bin spacing over a range of $0.03 \mathrm{~m}$. The lowest ADCP was initially deployed so the lower $0.01 \mathrm{~m}$ of the profiling range intersected the bed. The additional ADCPs were deployed with alongshore offsets of $0.2 \mathrm{~m}$ and vertical offsets of approximately $0.025 \mathrm{~m}$. The Vectrino II arrangement nominally provides the velocity profile from the bed level to roughly 0.07 $\mathrm{m}$ above the bed at $0.001 \mathrm{~m}$ increments. It is believed that this is the first time velocities in the swashzone boundary layer of a macrotidal beach have been recorded at this resolution. Other work has used a single Vectrino II on a microtidal beach to investigate near bed swash-zone flows (Puleo et al. 2012). The ADCPs were sampled at $100 \mathrm{~Hz}$. The main instrument contained a co-located UDM but also 2 buried pressure transducers (Figure 3B; Druck PTX1830). Buried pressure transducers were offset by $0.04 \mathrm{~m}$ in the vertical and the upper sensor was initially deployed $0.05 \mathrm{~m}$ below the bed.

Two different sensors were used to measure sediment concentration. Suspended sediment concentration (SSC) was recorded using a newly-constructed FOBS. This version of the FOBS consists of two separate probes (Figure 3B,d). The lower probe contains 10 fiber optic send-receive pairs separated by $0.01 \mathrm{~m}$ in the vertical. The lower 3 pairs were initially buried to enable data capture under mildly erosive conditions. The upper 10 pairs have vertical spacings of $0.01,0.02,0.03,0.03,0.04$, 0.05, 0.06, 0.06, 0.06, $0.07 \mathrm{~m}$. The FOBS was sampled at $4 \mathrm{~Hz}$. Sediment concentrations near the bed and in the sheet flow layer were measured using a conductivity concentration profiler (CCP; for a full 
description see Lanckriet et al. this issue and Lanckriet et al. In Review). The CCP is a new sensor that uses conductivity as a proxy for sediment concentration. Fresh and salt water both have conductivities several orders of magnitude higher than the essentially non-conductive sand. Thus, when sand is present within a particular measurement volume, the conductivity of that volume will decrease proportional to the sand/water ratio. Using conductivity as a proxy for sheet flow sediment concentration (SFSC) is not new (Horikawa et al. 1982; Ribberink and Al-Salem 1995) because other techniques such as optical backscatter are not appropriate under these high concentration scenarios. Past uses of conductivity for SFSC measured at a single elevation. The new CCP profiles the SFSC with $0.001 \mathrm{~m}$ vertical resolution over a range of $0.29 \mathrm{~m}$. The CCP consists of a removable probe with gold-plated electrodes and a PVC housing containing the electronics. The sensing mechanism relies on the 4-electrode approach ( $\mathrm{Li}$ and Meijer 2005) and circuitry within the housing multiplexes through the electrode array to return the SFSC profile. Sensors were deployed by burial with only the small measurement portion with cross-sectional area of $0.0016 \mathrm{~m}$ (thick) x $0.0056 \mathrm{~m}$ (wide) $\mathrm{x} \sim 0.04 \mathrm{~m}$ (high) exposed to the flow. Sensor burial reduces scour and wake effects and the surrounding sand helps support the thin, non-rigid probe tip. Three CCPs (Figure 3B,e) were deployed under the main instrument bar with alongshore separation of approximately $0.02 \mathrm{~m}$ and vertical separated to obtain a larger profile of the SFSC. During deployment, sensors were aligned by eye such that the electrodes were parallel to the cross-shore direction. CCPs were sampled at $4 \mathrm{~Hz}$.

A $4 \mathrm{~m}$ aluminium tower was erected in the dunes landward of the scaffold frame to mount several cameras. A Sony DFW-X710 firewire visible-band (RGB) camera with a 1024 x 768 pixel array sampled 5-minute image sequences at $5 \mathrm{~Hz}$ every 15 - 30 minutes during daylight hours when the swash-zone sensors were actively recording. A FLIR thermal infrared camera with a 640 x 480 uncooled microbolometer sensitive in the 7-14 $\mu \mathrm{m}$ band sampled 5-minute image sequences at $6.25 \mathrm{~Hz}$ every 15 - 30 minutes when the swash-zone sensors were actively recording. Finally, a miniature downward-looking visible-band camera (IBC) was deployed from the instrument bar to: 1) identify temporal phases of the swash cycle when bedload or sheet flow occur, and 2) the instant when sediment mobility ceased during the bed settling process when only a thin sheet of water remains on the beach face at the end stages of backwash. The IBC was sampled at 8 $\mathrm{Hz}$.

All sensors were surveyed into a local coordinate system using an electronic total station. The beach profile down the center of the scaffold frame and $25 \mathrm{~m}$ either side of the frame was measured before and after each tide. Surface sediment samples were collected along the central profile and the median grain size, $D_{50}$, was determined later using a settling tube. $D_{50}$ for Perranporth Beach is roughly $0.33 \mathrm{~mm}$, but does show a slight coarsening trend with increasing onshore distance (Figure 4).

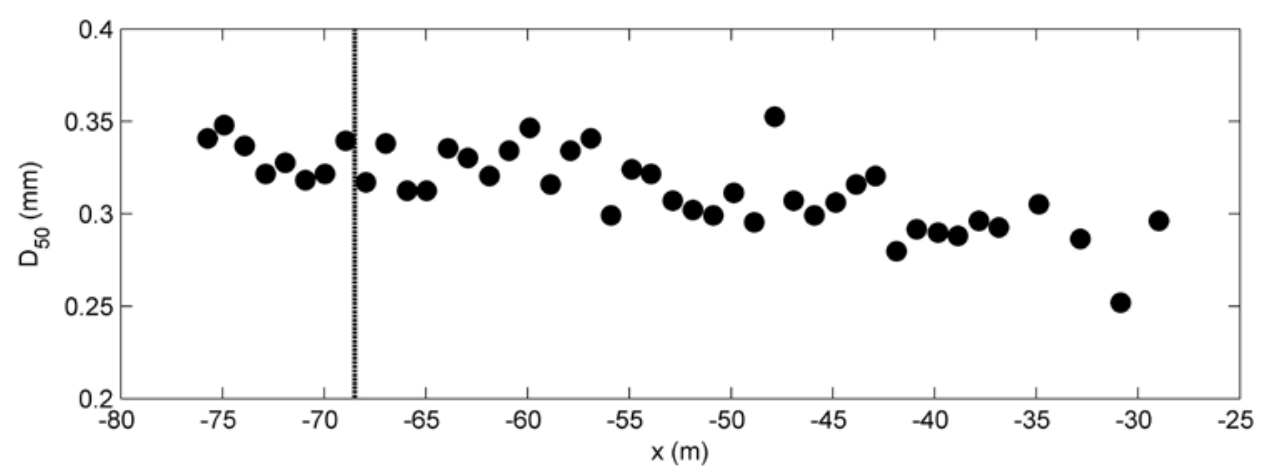

Figure 4. Median grain size as a function of cross-shore distance. The vertical line indicates the cross-shore position of the main instrument bar with the scaffold frame extending from roughly -30 to $-75 \mathrm{~m}$.

All sensors on the scaffold frame and the RGB and thermal cameras were cabled into a shorebased cabin for power, control and data acquisition. The numerous sensors and cameras were recorded on individual laptop computers. Time synchronization between sensing systems was achieved using GPS time and NetTime software. One laptop computer served as the master time server with other laptops receiving the time code either via wired or wireless connection. Each laptop updated its internal clock every second with the master time server to avoid clock drift. 
The elevation above the bed for sensors on the main instrument bar was measured following each tide. Vertical adjustments were made prior to the subsequent tide, as necessary, to return sensors to their initial elevations.

\section{RESULTS}

The beach profile from October 13, 2011 is shown in Figure 5A where the beach slope is roughly 1:45 near the main instrument bar that is roughly coincident with mean high water (MHW). Temporal surveying of the beach profile shows a consistent steepening of the upper beach face throughout the experiment (Figure 5B). The cumulative elevation change indicates erosion of roughly $0.1 \mathrm{~m}$ seaward of the main instrument bar (the white dashed in in Figure 5B). Corresponding accretion of roughly 0.1 $\mathrm{m}$ near the landward end of the scaffold frame, where the landward and seaward end of the scaffold frame are identified by the horizontal dashed black lines, is also observed. The cumulative flux of sediment per tide and integrated across the profile required to cause the observed profile change varies from about $0.5 \mathrm{~m}^{2}$ to $1.2 \mathrm{~m}^{2}$ (Figure $5 \mathrm{C}$ ). There is a flux increase in association with the increase in wave period around high tides 6 and 7 even though the significant wave height is smaller than earlier in the study period.
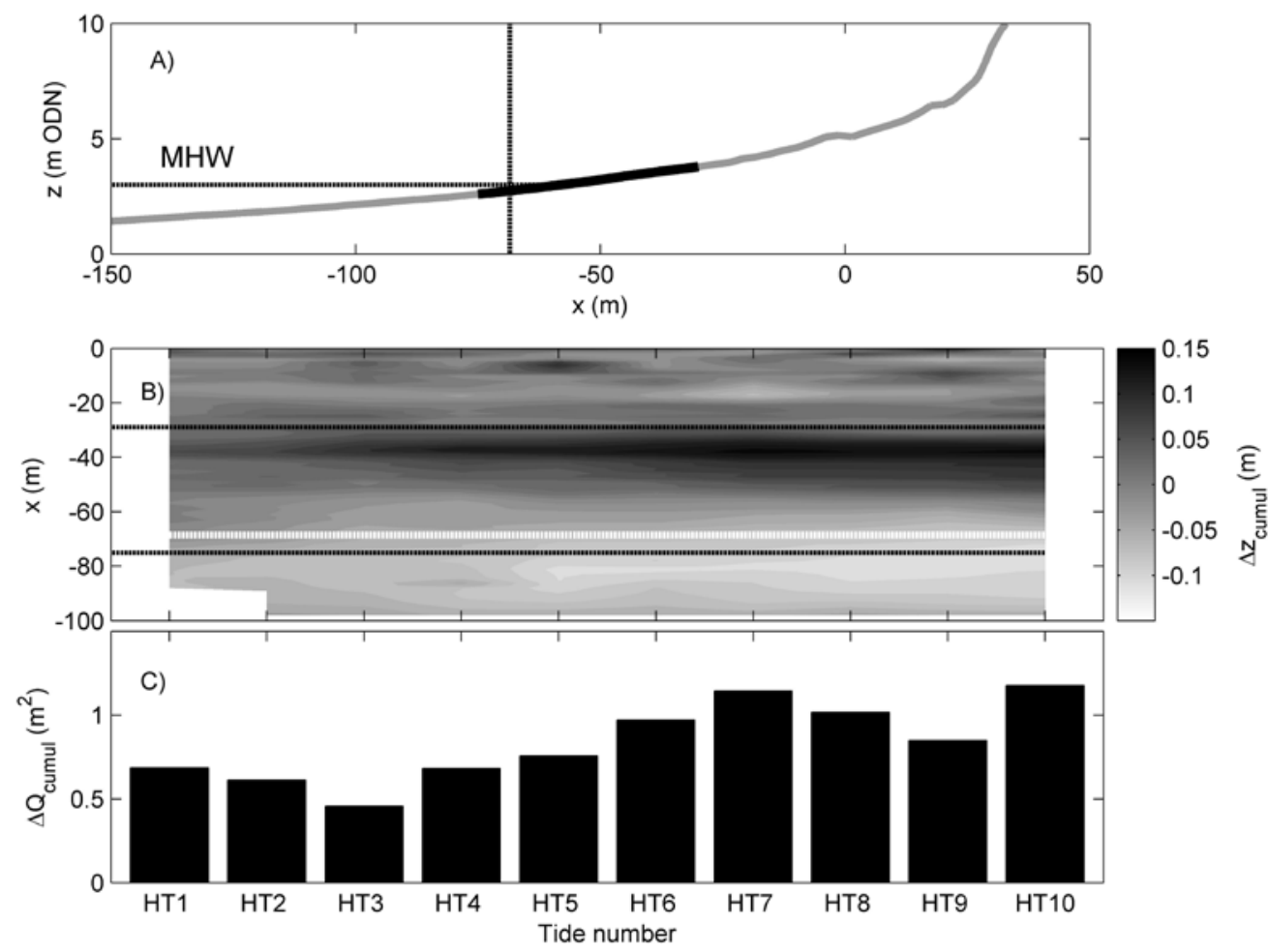

Figure 5. Morphologic variability during the BeST study. A) Beach profile from October 13, 2011 with scaffold frame identified in black. B) Cumulative elevation change for each tide. Horizontal black lines indicate seaward and landward edges of the scaffold frame. Horizontal white line indicates the location of the main instrument bar. C) Cumulative volumetric flux integrated over the tidal cycle and cross-shore distance.

Preliminary results indicate LiDAR and UDM data are correlated (Figure 6). Several instances, separated by roughly $1.5 \mathrm{~s}$, of bore propagation / runup over shallow water are shown. The leading edge of the runup is captured in both measurement techniques with the LiDAR data appearing somewhat noisier behind the bore. This finding is not surprising given the technical approach for each sensor. The UDM averages over a nominal area of approximately $0.28 \mathrm{~m}$ in radius ( $8^{\circ}$ beam angle) with a distinct concentration toward the centre of this region, whereas the LiDAR laser pulse area is estimated to have a diameter of $0.1 \mathrm{~m}-0.25 \mathrm{~m}$ at $20-50 \mathrm{~m}$ from the sensor. In addition the laser spot size will vary in shape due to the angle of the emitted beam and the specular nature of the turbulent, foamy/bubbly surface. Both sensors are able to return the sand surface level landward of the active swash zone. 

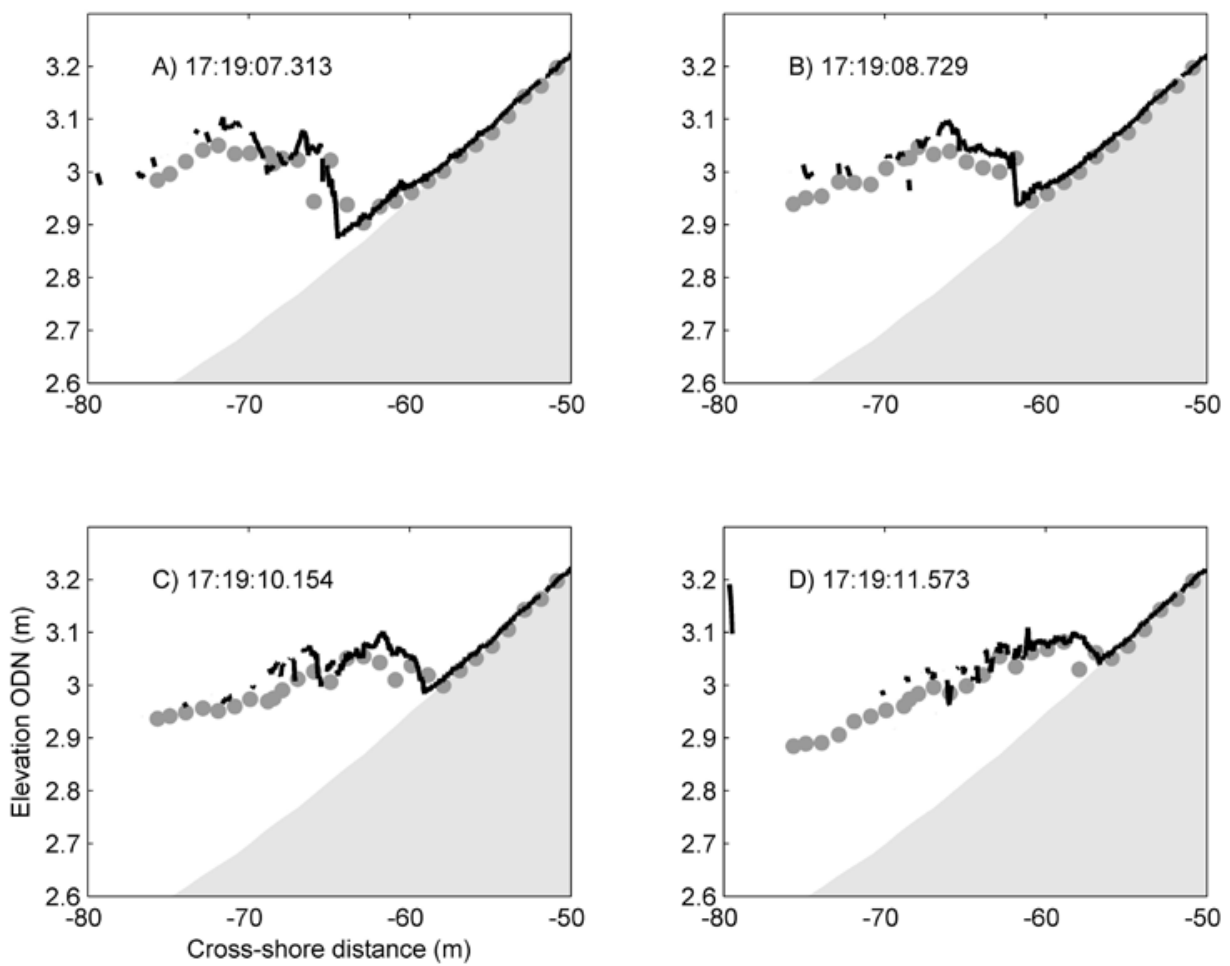

Figure 6. Comparison between UDM (dots) and LiDAR (black curves) for several instances of uprush motion identified by hours:minutes:seconds.milliseconds. Shaded area identifies the beach as determined from the post-tide 7 profile.

Figure 7 shows what are believed to be the first simultaneous measurements of near bed velocity, SSC and SFSC from a natural beach. Data are shown from October 13, 2011 during the ebb of tide 7. During this $\sim 10$ minute time series the water depth (Figure $7 \mathrm{~A}$ ) varies from 0 to over $0.7 \mathrm{~m}$. The crossshore velocity (Figure 7B) reaches nearly $2 \mathrm{~m} / \mathrm{s}$ in magnitude during onshore- and offshore-directed motions. The largest magnitude flows are observed during the latter stages of a large rundown and subsequent arrival of an incoming bore. Figure 7C shows the SSC from the lower 5 FOBS sensors. Time series are offset in the vertical by $400 \mathrm{~g} / \mathrm{l}$, the maximum concentration the sensor is capable of recording, for visual clarity. The lowermost sensor appears to be near the bed level for the majority of this time segment with reported concentrations approaching the $400 \mathrm{~g} / \mathrm{l}$ signal saturation. FOBS data indicate three primary suspension events at roughly 17:38:24, 17:39:40 and 17:41:16. Suspension pulses appear as double peaked surrounding the drop in concentration between peaks occurring near flow reversal. In general, the two peaks for a given suspension event are similar in magnitude for the lower 2-3 sensors. However, at times higher in the water column, SSC associated with onshoredirected motion exceeds that of the SSC associated with offshore-directed motion. Differences are likely attributed to the suspension mechanism. During onshore-directed motion, surface generated turbulence carries sediment higher into the water column. During offshore-directed motion for these events where the water depth approaches zero, turbulence originates form the bed and eddies are constrained by the free surface. Suspension events observed in FOBS data are correlated to sediment mobilization in the sheet flow layer (Figure 7D). Every other CCP channel is shown in Figure (7D) with subsequent time series offset by $1800 \mathrm{~g} / \mathrm{l}$. SFSC associated with offshore- and onshore -directed motion for the primary events is generally similar in magnitude with SFSC exceeding 1000 g/l. Large apparent SFSC when the CCP is exposed are due to non-conductive air and will be removed in future efforts. The latter half of the time series show CCP signal saturation followed by exposure indicating an accretion/erosion cycle on the order of 0 to $0.01 \mathrm{~m}$. Corresponding SSC data show little sediment suspended into the water column suggesting this bed level change is related to gradients in sheet flow transport rather than suspended sediment transport. The time history of the CCP and FOBS signal also indicates the difficulty in defining the instantaneous bed level. The $0.01 \mathrm{~m}$ resolution of the FOBS only provides a coarse resolution with respect to bed level variability identified in the CCP data. 
However, the highly-resolved CCP data indicates rapid bed level change such the bed level requires identification on short $(<1 \mathrm{~s})$ or instantaneous time frames rather than averaging over longer time blocks as has been performed in past work with FOBS data (Puleo et al. 2000).

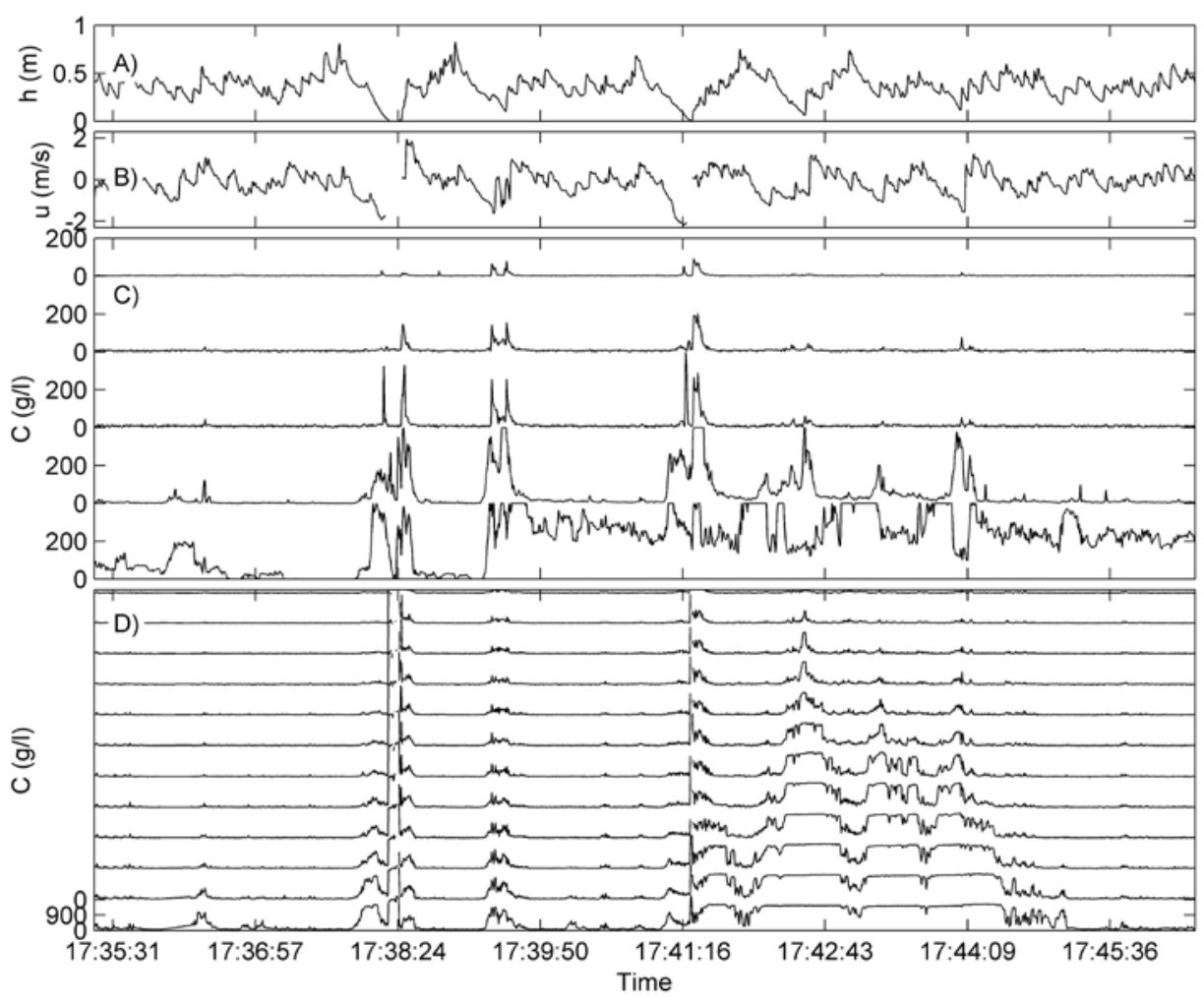

Figure 7. Velocity and sediment concentration during the ebbing tide 7 on October 13,2011 . A) Water depth from the upper buried pressure transducer. B) Cross-shore velocity from the lower EMCM. Positive velocities are onshore-directed. Gaps in the time series are when the water level was below the height of the current meter. C) SSC from the lower 5 FOBS sensors separated by $0.01 \mathrm{~m}$ in the vertical. Time series are offset vertically by $\mathbf{4 0 0} \mathrm{g} / \mathrm{l}$. D) SFSC from the CCP. Only ever other time series are shown and are separated by $0.002 \mathrm{~m}$ in the vertical. Time series are offset vertically by $1800 \mathrm{~g} / \mathrm{l}$.

\section{CONCLUSIONS}

A comprehensive study of swash-zone sediment transport was completed on a macro-tidal beach under energetic forcing conditions for 10 tidal cycles. Survey data showed vertical beach variability on the order of $0.1 \mathrm{~m}$ over the study period. Preliminary results were presented and indicated the uniqueness of the data set. Detailed measurements of the water free surface and inter-swash bed level collected using a LiDAR and ultrasonic distance meters were similar and will enable future extraction of the water free-surface slope, depth-averaged velocity and terms from the momentum equation for inferring forcing delivered to the bed. Preliminary results of simultaneous measurements of the suspended sediment concentration and sheet flow sediment concentration showed that sediment mobilization in the sheet layer is significant and cannot be ignored in swash-zone sediment transport studies. Future efforts will focus on quantifying the temporal variability of the SSC/SFSC ratio.

\section{ACKNOWLEDGEMENTS}

This material is based upon work supported by the National Science Foundation under Grant No. OCE-0845004. Additional support for this work was provided by the University of Delaware, the Delaware Department of Natural Resources and Environmental Control, the Award for Global Research, Internships, and Performances for Graduate Students at the University of Delaware, the Natural Environmental Research Council (Grant NE/G007543/1), an Australian Research Council Discovery Project (DP110101176), and the US-UK Fulbright Commission. 


\section{REFERENCES}

Blenkinsopp, C., M. E. Mole, I. L. Turner, and W. L. Peirson (2010b), Measurements of the timevarying profile across the swash zone using an industrial LIDAR, Coastal Eng., 57, 10591065.

Blenkinsopp, C. E., I. L. Turner, G. Masselink, and P. E. Russell (2011), Swash zone sediment fluxes field observations, Coast. Eng. Japan, 58, 28-44.

Horikawa, K., A. Watanbe, and S. Katori (1982), Sediment transport under sheet flow conditions, paper presented at 18th International Conference on Coastal Engineering, ASCE.

Horn, D. P., and T. Mason (1994), Swash zone sediment transport modes, Mar. Geol., 120(3-4), 309325.

Lanckriet, T. M., J. A. Puleo, and N. Waite (In Review), A conductivity-based profiler for sheet flow sediment concentration, IEEE J. Ocean. Eng.

Li, X., and G. C. M. Meijer (2005), A low-cost and accurate interface for four-electrode conductivity sensors, IEEE Transactions on Instrumentation and Measurement, 54, 2433-2437.

Masselink, G., D. Evans, M. G. Hughes, and P. Russell (2005), Suspended sediment transport in the swash zone of a dissipative beach, Mar. Geol.(216), 169-189.

Puleo, J. A., and T. Butt (2006), The 1st international workshop on swash-zone processes, Cont. Shelf Res., 26, 556-560.

Puleo, J. A., T. M. Lanckriet, and P. Wang (2012), Nearbed cross-shore velocity profiles, bed shear stress and friction on the foreshore of a microtidal beach, Coastal Eng., 68, 6-16.

Puleo, J. A., R. A. Beach, R. A. Holman, and J. S. Allen (2000), Swash zone sediment suspension and transport and the importance of bore-generated turbulence, J. Geophys. Res., 105(C7), 1702117044.

Ribberink, J. S., and A. A. Al-Salem (1995), Sheet flow and suspension in oscillatory boundary layers, Coastal Eng., 25, 205-225.

Turner, I., P. Russell, and T. Butt (2008), Measurement of wave-by-wave bed-levels in the swash zone, Coastal Eng., 55, 1237-1242.

Yu, Z., H. D. Niemeyer, and W. T. Bakker (1990), Site investigation on sand concentration in the sheet flow layer, ASCE, New York. 